\title{
ГЛАВА V.
}

УДК 34.096

\section{АНАЛИТИЧЕСКАЯ ОЦЕНКА ВАЖНЕЙШИХ НАПРАВЛЕНИЙ НОРМАТИВНОГО РЕГУЛИРОВАНИЯ САНИТАРНО- ЭПИДЕМИОЛОГИЧЕСКОГО БЛАГОПОЛУЧИЯ НАСЕЛЕНИЯ РОССИИ В ИСТОРИИ И СОВРЕМЕННОСТИ}

\author{
Печникова Ольга Глебовна \\ докт. юр. н., доцент, \\ профессор кафедры теории и истории государства и права \\ ФБОУ ВО РГУ нефти и газа \\ (национальный исследовательский университет) \\ имени И.М. Губкина
}

Аннотация: Системный анализ генезиса и эволюции процесса государственно-правового регулирования вопросов санитарноэпидемиологического благополучия населения России построен на рассмотрении правовых и иных источников. В данном контексте, автор произвел углубленную оценку исторических событий и нормативных актов, обобщивших правовой опыт, научные и медицинские достижения. Логическое формулирование и обоснование самостоятельных выводов опирается на концепцию целостного восприятия развития общества, государства и права. На этом конструктивном подходе, строится авторское утверждение о необходимости дальнейшего усовершенствования вопросов нормативного регулирования санитарно-эпидемиологического благополучия населения в Российской Федерации. Рекомендованный вектор, по мнению автора, позволяет закрепить приоритеты в системном законотворчестве, направленном на реализацию наиболее важных государственных задач не 
только на ранних этапах развития российского общества и государства, но и в современных реалиях; когда, нередко, стратегически значимым и жизненно необходимым, становится использование современных медицинских и иных научных знаний и достижений в сочетании с историко-правовым опытом и качественной оценкой фундаментальных вех эволюционного движения мирового прогресса.

Ключевые слова: право на охрану здоровья; нормативное регулирование санитарно-эпидемиологического благополучия в России; история правового закрепления медицинского права; правовые нормы Петра I, Екатерины II, Павла I; современные законы по санитарии и эпидемиологии в Российской Федерации.

\section{ANALYTICAL ASSESSMENT OF THE MOST IMPORTANT AREAS NORMATIVE REGULATION OF SANITARY AND EPIDEMIOLOGICAL WELL-BEING OF THE POPULATION OF RUSSIA IN HISTORY AND MODERN TIMES}

\section{Pechnikova O.G.}

Doctor of Law, Associate Professor, Professor of the Department of Theory and History of State and Law of the Federal Security Service of the Russian State University of Oil and Gas (National Research University) named after I.M. Gubkin

\footnotetext{
Abstract: A systematic analysis of the genesis and evolution of the process of state and legal regulation of issues of sanitary and epidemiological well-being of the population of Russia is based on the consideration of legal and other sources. In this context, the author made an in-depth assessment of historical events and regulations that summarized legal experience, scientific and medical achievements. The logical formulation and substantiation of independent conclusions is based on the concept 
of a holistic perception of the development of society, state and law. On this constructive approach, the author's statement is based on the need to further improve the issues of normative regulation of the sanitary and epidemiological wellbeing of the population in the Russian Federation. The recommended vector, according to the author, makes it possible to consolidate the priorities in systemic lawmaking aimed at the implementation of the most important state tasks not only at the early stages of the development of Russian society and the state, but also in modern realities; when, often strategically significant and vital, the use of modern medical and other scientific knowledge and achievements in combination with historical and legal experience and a qualitative assessment of the fundamental milestones of the evolutionary movement of world progress becomes.

Abstract: The right to health care; normative regulation of sanitary and epidemiological welfare in Russia; history of legal consolidation of medical law; legal norms of Peter I, Catherine II, Paul I; modern laws on sanitation and epidemiology in the Russian Federation.

Санитарно-эпидемиологическое благополучие населения, как конституционно закрепленное благо и ценность, имеет особую актуальность в современных реалиях, связанных с пандемией, касается каждого и отражает планомерную заботу государства о гражданах. Включение данных вопросов в формулировку ст. 41 Конституции РФ подчеркивает понимание законодателем важности мер в области санитарии и гигиены, противоэпидемической и профилактической направленности, необходимость их вынесения в число составляющих, в целом, определяющих вектор государственного развития и правового регулирования на внутригосударственном уровне и в международном взаимодействии.

Систематически, широко и на достаточно высоком уровне обсуждаются, принимаются и реализуются федеральные программы, отражающие пристальное внимание руководства страны к государственной, 
муниципальной и частной системам здравоохранения, где среди вопросов финансирования, строительства и ввода в эксплуатацию специализированных медицинских учреждений, разработки новых лекарств и вакцин, средств, необходимых для восстановления здоровья и реабилитации, затрагиваются также темы экологии, безопасного проживания населения и профилактики [1].

Необходимость проведения вакцинации населения, как одно из основных средств профилактики возникновения опасных инфекций, вызывающих, порой, катастрофические последствия, была осознана и стала приобретать государственное значение, еще в период существования Российской империи. Общественную известность имел исторический факт, связанный с датой - 12 октября 1768 г., когда Екатерина II сделала себе и своему сыну прививку от оспы. Позднее, 30 марта 1770 г. стало законом «Краткое и ясное наставление, каким образом содержать больного, как в натуральной, так и в прививной оспе по методу господина барона Димсдаля», где текст представлял собой рекомендации по диагностике, лечению, уходу за больными и оспопрививанию [2].

Вышеназванные события способствовали тому, что 14 мая 1772 г. вышел Сенатский указ «О поднесении 12 золотых медалей ея императорскому величеству, по случаю исцеления от прививания оспы» [3], согласно которому, от Правительствующего сената «ея императорскому величеству» на серебряном блюде были поднесены «12 золотых медалей со изображением, на одной стороне груднаго ея ... портрета, а на другой храма исцеления, пред которым лежит поверженная гидра; из храма исходит ея императорское величество, и с собою ведет его высочество, исцелившись от прививания оспы, а навстречу им идет обрадованная Россия со младенцами, с такою надписью: «собою подала пример»; а внизу: «1768 год октября 12 число», означающее день привития оспы».

Екатерина II и в дальнейшем продолжала выступать пропагандистом этой прививки, что подтвердил «Именной, данный правящему должность 
финляндскаго генерал-губернатора принцу Виртемберг-Штудгардскому указ от 6 декабря 1782 г. «О введении прививания оспы в Выборгской губернии»» [4]. В нем говорилось о пользе вакцинации, препятствующей развитию катастрофических последствий эпидемии, в частности, отмечалось, что «К отвращению всех тех бедствий, кои сия болезнь, когда она бывает натуральная, с собою приносит, введено было в общенародное применение оспопрививание». В материалах архива имеется заключение о практических разработках в сфере профессиональной деятельности чиновников Медицинской коллегии с названием «О коровьей оспе, вводимой в употребление в разных местах Российской империи» от 7 октября 1802 г. [5]

Следующим законом, ратующим за оспопрививание, на наш взгляд, следует назвать Именной указ Павла I, данный Киевскому, Черниговскому и Новгородско-Северскому генерал-губернатору графу РумянцевуЗадунайскому от 29 апреля 1787 г. «О заведении прививания оспы в Малороссийских губерниях» [6]. В этом же году, после выхода Доклада Медицинской коллегии, «Об учреждении Медицинских управ» от 19 января 1787 г. [7], - были основаны новые органы управления охраной «народного здравия», в числе функциональных обязанностей осуществлявшие контроль за санитарно-эпидемиологическим благополучием населения с учетом научных достижений и медицинских возможностей того времени.

В дальнейшем, профилактические меры, включающие вакцинацию от разного рода опасных инфекций и иные меры противоэпидемической направленности, вошли в полномочия иных министерств и ведомств, что может стать предметом отдельного рассмотрения. Говоря о профилактических прививках, следует лишь добавить, что, к моменту данной публикации, опыт нормативного регулирования ее организации и практического осуществления в России, насчитывает уже более, чем, 250 лет.

Еще более долгое время, более 300 лет прошло со времени основания первого отечественного госпиталя. Нормативный акт о возведении первого 
государственного лечебного учреждения, не сохранившийся до нашего времени, был подписан Петром I 25 мая 1706 г. В нем говорилось: построить «гофшпиталь», которому быть «за Яузою рекою, против немецкой слободы, в пристойном месте для лечения болящих людей». В «пристойном месте» располагались питейные заведения (за счет производимого налогообложения с них, частично покрывались расходы на лечение[8]); оно слыло свободными нравами, что, по-нашему мнению, влияло на то, что местные обитатели реже других жителей города задумывались о возможной опасности, исходящей от соседства с больными людьми и возможности эпидемии. Беспечному восприятию подобного соседства окружающим населением, способствовало также отсутствие знаний о влиянии бактериального или вирусного агента на возникновение и распространение заболеваний.

Во всех слоях общества, зачастую отсутствовала элементарная санитарная грамотность, как не было и организации систематической пропаганды и обучения населения этим крайне необходимым правилам. Потребность обращения внимания законодателя на данное направление государственной деятельности, формировалась постепенно, в результате обретения опыта, в случаях прибытия представителей российского флота в очаг эпидемии, достаточно часто возникавших в сопредельных государствах.

В связи с этим, при Петре I, нормативно определилась должность профоса - она являлась одной из первых, в отношении которой, нормативно закреплялись полномочия по организации санитарно-гигиенических, противоэпидемических мероприятий на военном корабле. Нормативный акт, определяющий его функциональные обязанности, назывался «Регламент о Управлении Адмиралтейства и верфи и часть вторая Регламента Морского от 5 апреля 1722 г. [9] (в составе которого присутствовал «Регламент о госпиталях, и о должностях определенных, при них комиссаров, докторов, писарей и прочих»).

Последний нормативный документ, в свою очередь, сыграл значительную роль уже через 13 лет в создании следующего «Генерального Регламента, - о 
госпиталях» [10], регламентирующего организацию и деятельность государственных медицинских учреждений. Основным отличием более позднего нормативно-правового акта, можно назвать то, что он являлся первым самостоятельным крупномасштабным документом медицинской регламентации XVIII в. и содержал положения, необходимые для обеспечения охраны здоровья военных, как основного контингента, согласно п. 12 гл. 1: «понеже военным служителям ... инаго госпиталя не имеется».

«Генеральный Регламент о госпиталях», впервые ввел главу с названием - «О строении госпиталя». Ей предусматривались санитарно-гигиенические нормы застройки объекта специального предназначения, предусмотренного для диагностики, лечения и восстановления здоровья больных; она состояла из 10 пунктов (тогда как Регламент 1722 г. - вообще не имел подобной главы).

В первую очередь, определялось место, под строительство указанного объекта: «начальственнее на то смотреть надлежит, чтоб оная на здоровом и отчасти высоком положении места при реке и на плодородной земле построена была». Такое расположение зданий, по нашему мнению, способствовало наилучшей вентиляции помещений. «Плодородные земли» нужны были для разведения огородных культур и лекарственных растений[11].

Научные знания еще не имели доказательств роли инфекционного или бактериального агента в качестве основных источников заражения; вместе с тем, недостаток медицинских кадров и экономические проблемы долгое время влияли на отсутствие значительного числа постоянно действующих государственных специализированных больниц инфекционного профиля.

Справедливо отметить, что к древним временам восходит эмпирическое понимание влияния ограничительных мер на разрастание эпидемий и число катастрофических последствий, в частности, недопущение контакта больных и здоровых, запрет перемещения из очага и прочее - все это включалось в порядок организации карантинов, осуществляемых силами военных. Волнообразность заболеваемости, зависимость от урожая и другие факторы, 
стали причиной того, что противоэпидемические меры не определялись законодателем как системные, постоянные в каждом регионе и требующие развития сети специализированных и постоянно действующих больниц инфекционного профиля.

В большинстве случаев, в очаг инфекционного заболевания командировался медик с лекарствами. Например, в архивных материалах Медицинской канцелярии, сохранились данные о том, что в качестве «студиоза для обучения латинского языка», 1 ноября 1738 г. заступил на службу в Санкт-Петербургский Сухопутный госпиталь копенгагенский студент по фамилии Цумп [12]. Безупречное выполнение им своих обязанностей [13], послужило тому, что 31 декабря 1738 г. его повысили в должности, «определив его при Санкт-Петербургской Сухопутной госпитали младшим доктором» [14]; а 29 сентября 1739 г., в звании доктора, он был командирован в Олонецк вместе с лекарствами [15].

В местах дислокации войск - медицинская помощь оказывалась во временно организованных учреждениях. К примеру, согласно «Положениям для временных военных госпиталей при большой действующей армии», вошедшего в Высочайше утвержденное учреждение Военного Министерства от 27 января 1812 г. [16], - подвижные госпитали устраивались «по назначению главнокомандующего» для лечения больных и раненых во время движения армии, следовали за ней, образуя несколько линий и предназначались для определенных корпусов.

Для оказания первой помощи раненым на месте сражения и перевозки их в подвижные госпитали, образовывались развозные госпитали. Больные венерическими болезнями, чесоткой и прочими «прилипчивыми болезнями» не лечились в подвижных госпиталях, во избежание распространения заболеваний, а направлялись в главные временные. При большом числе больных и раненых, полагалось использовать местные больницы гражданского ведомства «под надзором военной армейской полиции и на 
попечении медицинского ... ведомства». Подвижные госпитали могли перемещаться, для оказания необходимой медицинской помощи в местах наиболее ожесточенных сражений «по первому приказу».

Подвижные госпитали размещали в «казенных, общественных или обывательских строениях, а при их отсутствии - в палатках, шалашах или землянках, в сухих местах, где находилось от 10 до 30 человек раненых и больных так, чтобы расстояние между кроватями было не менее 70 см. В каждом главном и подвижном госпитале на 2 линии имелись отдельные палаты: 1) для выздоравливающих; 2) запасная; 3) для «пораженных антоновым огнем»; 4) для «одержимых прилипчивыми болезнями». Дополнительно нужно отметить, что в госпитале имелись и так называемые «особенные заведения». Они были представлены «заведениями для одержимых прилипчивыми и венерическими болезнями».

Итак, развивающаяся с 1707 г. сеть госпиталей, обеспечивала централизованное лечение военных, а вновь создаваемые государственные лечебные учреждения, организовывались по тем же основным принципам. Гражданское население стало иметь все большую возможность получать достаточно квалифицированную для своего времени медицинскую помощь, в том числе, и лица, имеющие инфекционные заболевания.

Негативный опыт, связанный с недооценкой опасности возникновения эпидемии, во время правление Екатерины II, послужил причиной принятия решения об организации специализированной больницы, предназначенной для лечения больных инфекционного профиля, что произошло благодаря Именному, данному Санкт-Петербургскому обер-полицеймейстеру Лопухину от 18 мая 1782 г. «Об открытии больницы для прилипчивых болезней» [17].

Этот закон, в свою очередь, стал началом практического осуществления планов по их строительству в других городах. Возвращение к противоэпидемическим мероприятиям во вновь издаваемых законах, демонстрировало их неизменную актуальность для нашего государства. 
Мы уже упомянули ранее о должности профоса на военных кораблях, нормативно утвержденной Петром I. Профос являлся одним из первых штатных военных сотрудников, имевших основные нормативно закрепленные функциональные обязанности по организации санитарно-гигиенических, противоэпидемических мероприятий в условиях крайне ограниченного пространства на военном корабле и значительной возможности контакта с источником заражения при прибытии в очаг инфекции. Данное должностное лицо, во исполнение положений «Регламента о Управлении Адмиралтейства и верфи и части второй Регламента Морского» от 5 апреля 1722 г. [18], кроме прочего, также осуществляло применение телесных наказаний в качестве устрашающих мер за невыполнение предусмотренных мер. Еще более жесткие санкции, вплоть до смертной казни, предусматривались за несоблюдение нормативно утвержденных карантинных предписаний в условиях массовых эпидемий, что мы подробнее рассмотрим далее.

Проводя историко-правовые параллели, следует также отметить еще один важнейший вопрос нормативного регулирования, вошедший в формулировку современного российского закона. Так в ст. 2 гл. 2 Федерального закона от 21.11. 2011 № 323-Ф3 (ред. от 30. 04. 2021) «Об основах охраны здоровья граждан в Российской Федерации» соблюдение прав граждан в сфере охраны здоровья и обеспечение государственных гарантий, связанных с этими правами, признается одним из главных принципов охраны здоровья [19]. При этом согласно ст. 98 гл. 13 того же закона, ответственность за обеспечение реализации гарантий, соблюдение прав и свобод в сфере охраны здоровья, нормативно регламентированную в Российской Федерации, возлагается на органы государственной власти и органы местного самоуправления и должностные лица. О последних, упоминается и в ст. 41 Конституции РФ, где, в частности, указывается, что сокрытие должностными лицами фактов и обстоятельств, создающих угрозу для жизни и здоровья людей, влечет за собой ответственность в соответствии с федеральным законом [1]. 
Пристальное внимание государства, обращенное в сторону разработки, усовершенствования и неукоснительного соблюдения санитарнопротивоэпидемических мероприятий, связано, вместе с тем, и с печальными страницами нашей истории, отразившими катастрофические людские потери от опустошающих эпидемий, к примеру, связанными с эпидемией конца XVIII века [20]. Правовые нормы формировались и оттачивали свои формулировки постепенно, обобщая многовековой опыт борьбы с болезнями и их распространением [21].

Мы уже упомянули о том, что, жесткие и, порой, жестокие санкции могли грозить нарушителю предписанных ограничительных санитарнопротивоэпидемических мер, согласно правилам Высочайше утвержденного «Устава о карантинах» от 21 августа 1818 г. [22]. Все следственные действия по «карантинным преступлениям» проводились карантинной конторой, а на заставе - управляющим конторой. Преступник, в любом случае, находился в карантинной конторе. В случае необходимости назначения смертной казни, материалы направлялись в Уголовную палату губернии, где рассматривались в первую очередь. Остальные решения (штраф, «задержание на хлебе и воде», телесные наказания) - нуждались в утверждении губернатора или «гражданского начальника».

Учитывая трагические последствия от несоблюдения карантинных мер, смертная казнь назначалась: 1) нарушившим присягу и лжесвидетельствовавшем о состоянии здоровья «прибывших с ним людей на судне или сухим путем»; 2) уличенным в подделке документа, используемого для сокращения или отмены карантина; 3) самовольно покинувшим судно или карантинный дом с любым намерением; 4) оказавшим сопротивление карантинной службе; 5) совершившим попытку побега «от надзора караульного начальства» (в последнем случае «дозволялось убивать его до смерти всякому карантинному чиновнику, караульной страже и даже обывателю»); 6) при подтверждении факта выноса, передачи и прочих вещей, 


\section{ОБЩЕСТВО, ЭКОНОМИКА, ПРАВО: АКТУАЛЬНЫЕ ВОПРОСЫ И ВЕКТОРЫ РАЗВИТИЯ}

из внутренней части карантина, проникновения на корабль, проходящего дезинфекцию; 7) в отношении карантинной стражи и других лиц, при тайной выгрузке, а также провозе товаров, минующих карантин. Товар, задержанный карантинным чиновником при попытке провоза мимо карантина, после дезинфекции, отдавался «в награждение», причем, если такое случалось более 5 раз, он получал «особенное от Правительства награждение».

Денежные штрафы грозили за умышленное касание вещей или людей, находящихся в карантинном доме. В качестве наказания использовалось содержание под стражей «на хлебе и воде» от 2 до 5 недель, далее шло увольнение со службы с запретом занимать любые должности. В отношении «нижних карантинных служителей», применялись телесные наказания: «в первый раз - 50 ударов, во второй - 100 и т.д.», а «нижние военные служители» наказывались шпицрутенами. При пятикратных нарушениях в течение года виновных «отсылали на год на публичную работу». Для выполнения наиболее опасных работ применялся труд осужденных за преступления. За «упущения» их наказывали в первый раз - 25 ударами плетьми, во второй - 75 и т.д. Если более пяти нарушений в течение навигационного периода - после телесных наказаний, их отсылали на рудники в Сибирь. Лица, донесшие о преступлении, освобождались от наказания и штрафа [23].

Выше названные правила для кораблей Военного ведомства в дальнейшем утверждались Сенатским указом, по Высочайше утвержденным Положениям Комитета Министров «Об особых карантинных правилах для военных судов» [24] от 7 мая 1823 г. и «О мерах, принятых к прекращению появившейся в Астрахани болезни Cholera Morbus» [25] от 6 октября 1823 г.

Около двух веков прошло с того времени, за это время общество обрело значительный опыт, знания, революционные научные достижения, разработало нормативные основы правового регулирования государственного развития. В связи с этим, необходимо отметить также тенденцию смягчения наказаний 
в отношении преступивших закон, в частности, связанную с мораторием на смертную казнь и демократическими преобразованиями в обществе.

Тем ни менее, ст. 236 УК РФ от 13.06.1996 г. (в ред. от 08.04.2021) предусматривает санкции за нарушение санитарно-эпидемиологических правил, повлекшее по неосторожности массовое заболевание или отравление людей в виде штрафа в размере до восьмидесяти тысяч рублей или в размере заработной платы или иного дохода осужденного за период до шести месяцев, либо лишение права занимать определенные должности или заниматься определенной деятельностью на срок до трех лет, либо обязательными работами на срок до трехсот шестидесяти часов, либо исправительными работами на срок до одного года, либо ограничением свободы на срок до одного года. А то же деяние, повлекшее по неосторожности смерть человека, - наказывается обязательными работами на срок до четырехсот восьмидесяти часов, либо исправительными работами на срок от шести месяцев до двух лет, либо принудительными работами на срок до пяти лет, либо лишением свободы на тот же срок [26].

Кроме санкций, законодатель в другом Федеральном законе, изданном после 1996 г., обращается к иному ракурсу, представляющему несомненный интерес, тем самым, демонстрируя, что современное видение предмета нормативного регулирования является многогранным.

Так, особый концептуальный подход к разработке нормативной регламентации прослеживается в Федеральном законе от 30.03.1999 N 52-Ф3 (в ред. от 13.07.2020) «О санитарно-эпидемиологическом благополучии населения», направленном на обеспечение одного из основных условий реализации конституционных прав граждан на охрану здоровья и благоприятную окружающую среду.

В нем, в частности раскрываются такие основные категории, как санитарно-эпидемиологическое благополучие населения, федеральный государственный санитарно-эпидемиологический надзор, среда обитания 
человека и ее факторы, вредное воздействие на человека, благоприятные условия жизнедеятельности человека, безопасные условия для человека, санитарно-эпидемиологическая обстановка, гигиенический норматив, санитарно-эпидемиологические требования и др.

По нашему мнению, данный подход позволяет конкретизировать государственные задачи и существенно облегчить правоприменение, предоставляя возможность практическому использованию закона повлиять на качественную оценку адекватности нормативного регулирования, позволяющему отмечать и усиливать его положительные стороны, выявлять и устранять недостатки. На наш взгляд, в плане улучшения применения его основных положений, существенную помощь может оказать реализация возможности включения в него бланкетных норм.

Современные реалии требуют дальнейшего усовершенствования нормативного регулирования вопросов санитарно-эпидемиологического благополучия населения в Российской Федерации, жизненно важного на всех этапах развития общества и государства и планомерно использующего современные научные знания и медицинские достижения в сочетании с историко-правовым опытом и качественной оценкой фундаментальных вех эволюционного движения мирового прогресса.

\section{Список литературы}

1. Конституция Российской Федерации от 12.12.1993 (ред. от 04.07.2020).

2. Полное собрание законов Российской империи (далее - ПСЗ РИ). Собр. 1. Т. XIX. СПб., 1830. № 13445.

3. ПСЗ РИ. Собр. 1. Т. ХІХ. СПб., 1830. № 13801.

4. ПСЗ РИ. Собр. 1. Т. ХХІ. СПб., 1830. № 15607.

5. Российский государственный архив древних актов (далее - РГАДА). Ф. 344. Оп. 3. Кн. 1. Д. 4.

6. ПСЗ РИ. Собр. 1. Т. ХХІІ. СПБ., 1830. № 16533. 
7. ПСЗ РИ. Собр. 1. Т. ХХІV. СПб., 1830. № 17743.

8. ПСЗ РИ. Собр. 1. Т. ІV. СПб., 1830. № 2074.

9. ПСЗ РИ. Собр. 1. Т. VI. СПб., 1830. № 3937.

10. ПСЗ РИ. Собр. 1. Т. ІХ. СПб., 1830. № 6852.

11. РГАДА. Ф. 346. ОП. 2. Кн. 52. Д. 332.

12. РГАДА. Ф. 346. ОП. 1. Кн. 19. Д. 521.

13. РГАДА. Ф. 346. Оп. 1: Кн. 19. Д. 537; Кн. 31. Д. 475.

14. РГАДА. Ф. 346. ОП. 1. Кн. 28. Д. 302.

15. РГАДА. Ф. 346. ОП. 1. Кн. 31. Д. 491.

16. ПСЗ РИ. Собр. 1. Т. ХХХІІ. СПб., 1830. № 24971.

17. ПСЗ РИ. Собр. 1. Т. ХХІ. СПб., 1830. № 15399.

18. ПСЗ РИ. Собр. 1. Т. VI. СПб., 1830. № 3937.

19. Федеральный закон «Об основах охраны здоровья граждан в Российской Федерации» № 323-Ф3 от 21.11.2011 (ред. от 30. 04. 2021).

20. Печникова О.Г. Становление российского санитарного законодательства // Памятники права в период правления Павла I. T. VII. // Учебно-научное пособие под ред. д.юр. наук проф. Р.Л. Хачатурова. М.: Юрлитинформ, 2014. С. 441 - 449.

21. Печникова О.Г. Государственно-правовое регулирование охраны «народного здравия» в России XVI - начала XIX в.: монография. М.: Юрлитинформ, 2016. - 496 с.

22. ПСЗ РИ. Собр. 1. Т. ХХХУ. СПб., 1830. № 27490.

23. ПСЗ РИ. Собр. 1. Т. ХХХVIII. СПб., 1830. № 29452.

24. ПСЗ РИ. Собр. 1. Т. ХХХVIII. СПб., 1830. № 29623.

25. Уголовный кодекс Российской Федерации от 13.06.1996 (в ред. от 17.04 2017).

26. Федеральный закон «О санитарно-эпидемиологическом благополучии населения» от 30.03.1999 № 52-Ф3 (в ред. от 13.07.2020). 